\title{
4 \\ APRENDIZAJE AUTORREGULADO Y FOMENTO DE COMPETENCIAS EN DOS ASIGNATURAS DE MASTER A TRAVÉS DEL EMPLEO DE PLANTILLAS DE EVALUACIÓN, MÉTODO DEL CASO, ROLE-PLAYING Y VIDEO DIGITAL
}

(SELF-REGULATED LEARNING AND PROMOTION OF COMPETENCES IN TWO MASTER-LEVEL SUBJECTS, BY MEANS OF ASSESSMENT TEMPLATES, CASE METHOD, ROLE-PLAYING AND DIGITAL VIDE0)

Sonia Lara y Sonia Rivas

Universidad de Navarra

\section{RESUMEN}

En este artículo se presentan las experiencias y opiniones recogidas de los alumnos durante tres cursos académicos de dos asignaturas ofertadas en el Master Oficial en Matrimonio y Familia de la Universidad de Navarra. Las asignaturas son "Educación familiar en la infancia" y "Modelos de orientación en psicopedagogía familiar". Se trata de una propuesta metodológica para fomentar la integración de la docencia práctica de dos asignaturas planteando una metodología centrada en el alumno que fomente el aprendizaje autorregulado y autónomo, así como el desarrollo de competencias en los alumnos, a través del empleo del Role-playing, el Método del Caso, las Plantillas de evaluación o rubrics y el vídeo digital. La peculiaridad de la experiencia mostrada radica en que forma parte de un Master de modalidad on-line que combina unas sesiones presenciales al finalizar la docencia del curso para poner en práctica los contenidos estudiados a lo largo del curso académico.

\section{ABSTRACT}

Student experiences and opinions from an Online Master in Marriage and the Family at the University of Navarra are analysed through three academic years. The specific courses used were "Family Education in Early Childhood" and "Models of Guidance in Family Psychology". A learning-centred teaching methodology that encourages an autonomous and self-regulated learning, as well as the development of competences in students, are experienced by the 
students, through a few classes in which student assistance is required at the end of the academic year. Role Playing, Case Method, Rubrics and digital video are the tools for this learned-centred teaching methodology.

\section{INTRODUCCIÓN}

El proceso de convergencia europea plantea un nuevo enfoque metodológico que transforma nuestro sistema educativo basado en la enseñanza, a otro basado en el aprendizaje. Además, como es bien sabido, se pone el énfasis en el desarrollo de competencias específicas para la profesión, así como genéricas que preparen a los futuros graduados de la universidad para su ejercicio profesional. En la experiencia que describimos a continuación hemos pretendido a través de la innovación metodológica ofrecer a los alumnos herramientas para el desarrollo de las competencias tanto instrumentales (capacidad de análisis y síntesis; capacidad de organizar y planificar; resolución de problemas; toma de decisiones), interpersonales (trabajo en equipo; apreciación de la diversidad y multiculturalidad; compromiso ético), sistémicas (capacidad de aplicar los conocimientos en la práctica; capacidad para generar nuevas ideas; habilidad para trabajar de forma autónoma), como por supuesto competencias específicas propias de la profesión de Orientador y Educador familiar como es el empleo de la técnica de la entrevista de orientación, y la aplicación y uso estratégico de los principios teóricos a las circunstancias específicas del problema al que se enfrenta (Cfr. Vélaz de Medrano, 2008).

El proceso de Bolonia se sustenta en tres principios (MEC, 2005): mayor implicación y autonomía del estudiante, utilización de metodologías más activas, y papel del profesorado como agente creador de entornos de aprendizaje que estimulen a los alumnos. El enfoque de la enseñanza centrada en el alumno es el paraguas que quizá mejor alberga las directrices sobre el EEES marcadas en Bolonia. "[...] Sus principios tratan de responder a las demandas de una enseñanza más activa orientada al aprender a aprender. Sus raíces últimas se encuentran en un nuevo paradigma del aprendizaje que, como Beltrán (1996) explica, tiene como principales rasgos ser activo, cognitivo, constructivo, significativo y autorregulado. Este último aspecto, la autorregulación, pretende destacar la capacidad y autonomía de la persona para aprender, que, por otra parte le permitirá salvar las barreras que impone el continuo cambio. Así, si una de las metas es formar personas dispuestas a aprender de modo permanente, una de las principales funciones del docente es enseñar a autorregular el aprendizaje (Dembo, 2001; Zimmerman, 2002)" (Lara, Chocarro y Sobrino, 2007, p. 230). 
Según Chocarro (2006) y Chocarro, González-Torres y Sobrino (2007) este enfoque otorga un papel más activo al alumno para conseguir que se implique en su aprendizaje y sea así más consciente del mismo. La idea es "contar con" el alumno durante el proceso de enseñanza-aprendizaje, y por ello se habla de que la responsabilidad del aprendizaje debe ser compartida entre profesor y alumno (Weimer, 2002). Este modo de entender el proceso de aprendizaje supone un cambio de papel para el profesor, que adquiere el rol de facilitador en cuanto que, por un lado, debe establecer un contexto que incentive la autonomía, y, por otro, guíe al alumno en su aprendizaje.

Para poder combinar estos dos elementos vitales del aprendizaje centrado en el alumno (autonomía y guía/estructura), los procesos de andamiaje que debe ofrecer el profesor se convierten en un elemento fundamental. Como es bien sabido, el andamiaje o scaffolding es una metáfora que designaría una plataforma (andamiaje) temporal de ayudas que sirve mientras se consolidan y se incorporan, nuevas habilidades al conocimiento que ya posee el alumno para construir conocimientos más avanzados. Las ayudas (o andamiajes) que se le ofrecen al alumno están basadas en el modelo de experto/principiante (Bransford, Brown y Cocking, 2001). El profesor puede plantear al menos dos alternativas para andamiar el trabajo de los alumnos, ofrecer guías del proceso a seguir en el trabajo así como plantillas de evaluación que informan de los criterios y estándares de excelencia que se van a tener en cuenta en la evaluación del trabajo. En la experiencia que mostramos en las siguientes páginas hemos introducido estos dos tipos de andamios o ayudas:

- Las guías del proceso se ofrecen con explicaciones verbales al gran grupo, y con el material impreso del dossier de las sesiones en el que se incluye: concreción del tiempo previsto para cada tarea y plantillas para rellenar cada una de las partes del trabajo.

- Las plantillas de evaluación que ofrecen de forma detallada los criterios y estándares que se tendrán en cuenta para evaluar cada una de las partes del trabajo a realizar.

La propuesta de este artículo es presentar la experiencia y opiniones recogidas de los alumnos durante tres cursos académicos (2005-2006, 20062007 y 2007-2008) de dos asignaturas ofertadas en el Master Oficial en Matrimonio y Familia (1) de la Universidad de Navarra. Las asignaturas son "Educación familiar en la infancia" (en adelante $\mathrm{n}^{\circ} 12$ ) y "Modelos de orientación en psicopedagogía familiar" (en adelante $\mathrm{n}^{\circ} 16$ ). En concreto, se trata de una propuesta metodológica para fomentar la integración de la docencia práctica de dos asignaturas planteando un metodología centrada en el alumno que fomente el aprendizaje autorregulado y autónomo, así como el de- 
sarrollo de competencias en los alumnos, a través del empleo del Role-playing, el Método del Caso, las Plantillas de evaluación o rubrics y el vídeo digital.

\section{ESTRATEGIAS DIDÁCTICAS EMPLEADAS}

La docencia del Master en Matrimonio y Familia combina la modalidad online con sesiones presenciales-prácticas en las que se ven algunos contenidos de las asignaturas. Durante el mes de agosto, hay una quincena de sesiones presenciales en las que se ven algunos contenidos de las asignaturas estudiadas durante el año. La experiencia que mostramos corresponde a las sesiones presenciales del mes de agosto de tres cursos académicos.

Con el objetivo de aunar y poner en práctica lo estudiado en las dos asignaturas se pide a los alumnos que diseñen y filmen dos entrevistas de orientación en las que aplican las técnicas y la teoría estudiada en dos asignaturas. Para ello se emplea el método del caso, trabajo en pequeño grupo, el role-playing y el empleo de plantillas de evaluación o rúbricas. El tiempo dedicado para estas sesiones es de día y media en jornada de mañana (9:302:00) y tarde (3:00-6:00).

A continuación describimos brevemente el procedimiento seguido (cfr. Lara y Rivas, 2007):

Las profesoras de las asignaturas del master hacen una introducción en la que dan las pautas necesarias para realizar el trabajo, y entregan un dossier con el material que deben emplear. En él se recoge el programa de las sesiones presenciales, el texto de un Caso, unas plantillas para elaborar los guiones de las entrevistas, un cuadro resumen de los contenidos teóricos más importantes vistos en una de las asignaturas, los criterios de evaluación y una plantilla de evaluación.

A continuación se lleva a cabo un análisis del caso "La Familia Orduna" primero de forma individual y luego, con la ayuda de la profesora, con todo el grupo de clase. El caso ha sido realizado ad hoc para las sesiones presenciales de la asignatura. El objetivo es que todos los alumnos partan de una misma situación para plantear los aspectos que son susceptibles de análisis y orientación, y así puedan comparar finalmente las diferentes soluciones planteadas por otros grupos.

Una vez analizado el caso, se pasa a trabajar en pequeños grupos de entre seis y siete personas para profundizar en el caso. A partir de este momento los alumnos son divididos en aulas diferentes y cuentan con el ase- 
soramiento de las profesoras que visitan continuamente las diferentes aulas. Las tareas que deben realizar en el tiempo asignado son:

a. Concretar el problema que será objeto de orientación en las entrevistas de orientación y el enfoque que darán a las mismas.

b. Elaborar un guión de las entrevistas de orientación.

c. Filmar las entrevistas de orientación, realizando pequeñas dramatizaciones o role-playing de los guiones elaborados.

Para facilitar el buen funcionamiento del grupo y conseguir la cooperación, desde el principio se asigna a los alumnos diversos roles, todos ellos relacionados entre sí (cfr. Johnson, Johnson y Holubec, 1994). Para las fases (a) de concreción del problema, y (b) de elaboración del guión se pide a los alumnos que ejerzan los siguientes roles:

Encargado de fomentar la participación: Tiene que asegurar que todos los miembros del grupo participen. Si existe algún miembro que no habla debe interpelarlo para que exprese su opinión.

Orientador: Debe orientar al grupo revisando las instrucciones, reafirmando el propósito de la tarea asignada, marcando los límites de tiempo y sugiriendo procedimientos para realizar la tarea con la mayor eficacia posible.

Encargado de aclarar/parafrasear: En ocasiones deberá reformular lo que dicen otros miembros para clarificar los puntos tratados.

Encargado de llevar un registro: Debe anotar las decisiones del grupo y redactar el guión de la entrevista.

Supervisor de las técnicas: Debe controlar que se empleen las suficientes y necesarias técnicas a lo largo de las dos entrevistas.

Encargado de buscar fundamentos: Debe encargarse de pedir a los miembros del grupo que fundamenten sus respuestas y conclusiones con hechos o razonamientos.

Encargado de ofrecer apoyo: Debe brindar apoyo verbal y no verbal mediante la consulta y el elogio de las ideas y las conclusiones de los demás.

Para la fase (c) de filmación de las entrevistas se pide a los alumnos que distribuyan los roles que aparecen en el caso de "La familia Orduna" en- 
tre: los actores de las entrevistas (que coinciden con los de padre, madre y orientador); el encargado de manejar la cámara; y varios apuntadores que supervisarán que los actores siguen las ideas recogidas y elaboradas por el grupo en el guión de la entrevista.

En los cursos 05-06 y 06-07 se entregaron unas fichas en las que se explicaban el funcionamiento de los diferentes roles. En el curso 07-08 los roles se explicaron verbalmente de forma personalizada a cada grupo.

Por último, se realiza la puesta en común de los trabajos realizados por los pequeños grupos a toda la clase. Cada grupo presenta brevemente el enfoque que ha realizado de las entrevistas y visiona el vídeo grabado. En los dos últimos años, por diversos problemas técnicos, algunos grupos tuvieron que presentar su trabajo realizando, delante del gran grupo, el role-playing que habían filmado.

A partir del curso 06-07 se introdujo como novedad, una plantilla de evaluación o rubrics (ver Anexo 1). Como se ha descrito en el apartado anterior el objeto de ofrecerles estas plantillas es guiar al alumno en la correcta realización del trabajo grupal, así como en fomentar el trabajo autónomo. Dicha plantilla recoge los siguientes apartados: a) análisis del contenido del caso: recogida de información, análisis del problema, plan de acción ofrecido a los padres; b) empleo de las técnicas de la entrevista en el proceso de orientación; c) elaboración del vídeo; d) presentación del trabajo; e) trabajo en grupo.

En la Tabla 1 pueden verse resumidamente las diferentes innovaciones y variaciones llevadas a cabo a lo largo de los tres cursos académicos. Las diferencias más significativas han sido:

- la ampliación del contenido del Caso, en el curso 07-08;

- la presentación de los trabajos realizados por los alumnos al gran grupo en formato de escenificación en el curso 07-08, en lugar de visionar el vídeo filmado, debido a los problemas técnicos por los diferentes formatos digitales y estándares americanos en los que se habían grabado las entrevistas;

- la introducción de las plantillas de evaluación o rubrics en el dossier de los alumnos en el curso 06-07, y una mejora de las mismas en el curso 07-08. 
Tabla 1. Innovaciones metodológicas de los tres cursos (GG: gran grupo, PG: pequeño grupo)

\begin{tabular}{|c|c|c|c|}
\hline & $05-06$ & $06-07$ & 07-08 \\
\hline Caso & $\begin{array}{l}\text { Lectura y análisis in- } \\
\text { dividual del caso } \\
\text { Análisis guiado por } \\
\text { la profesora en GG. }\end{array}$ & Ídem curso 05-06. & $\begin{array}{l}\text { Ampliación del con- } \\
\text { tenido del Caso } \\
\text { Lectura y análisis in- } \\
\text { dividual del caso } \\
\text { Análisis en PG y dis- } \\
\text { cusión en GG guiada } \\
\text { por la profesora. }\end{array}$ \\
\hline $\begin{array}{l}\text { Guiones de } \\
\text { las entrevistas }\end{array}$ & Elaboración en PG. & Ídem curso 05-06. & Ídem curso 05-06. \\
\hline Role-playing & Elaboración en PG. & Ídem curso 05-06. & Ídem curso 05-06. \\
\hline Filmación & Elaboración en PG. & Ídem curso 05-06. & Ídem curso 05-06. \\
\hline $\begin{array}{l}\text { Visionado de } \\
\text { las entrevistas } \\
\text { realizadas en } \\
\text { PG al GG }\end{array}$ & $\begin{array}{l}\text { Visionado de los ví- } \\
\text { deos. }\end{array}$ & $\begin{array}{l}\text { Visionado de los ví- } \\
\text { deos de la mayoría } \\
\text { de los grupos, al- } \\
\text { gunos grupos por } \\
\text { problemas técnicos } \\
\text { realizan las dramati- } \\
\text { zaciones. }\end{array}$ & $\begin{array}{l}\text { Dramatización de } \\
\text { las entrevistas reali- } \\
\text { zadas en PG ante el } \\
\text { GG. }\end{array}$ \\
\hline $\begin{array}{l}\text { Plantillas de } \\
\text { evaluación }\end{array}$ & No se introdujo. & $\begin{array}{l}\text { Se incluye Plantilla } \\
\text { con criterios de eva- } \\
\text { luación del análisis } \\
\text { del caso, elaboración } \\
\text { de guiones, vídeo y } \\
\text { presentación del tra- } \\
\text { bajo. }\end{array}$ & $\begin{array}{l}\text { Ídem curso 06-07, } \\
\text { pero con una planti- } \\
\text { lla simplificada y } \\
\text { mejorada. }\end{array}$ \\
\hline Roles & $\begin{array}{l}\text { Etiquetas para dina- } \\
\text { mizar el trabajo de } \\
\text { los PG. }\end{array}$ & $\begin{array}{l}\text { Etiquetas para dina- } \\
\text { mizar el trabajo de } \\
\text { los PG. }\end{array}$ & $\begin{array}{l}\text { Asignación verbal de } \\
\text { los roles para dina- } \\
\text { mizar el trabajo de } \\
\text { los PG. }\end{array}$ \\
\hline
\end{tabular}

\section{INSTRUMENTO DE MEDIDA}

Para recabar la información se elaboró un cuestionario para conocer las opiniones de los alumnos sobre los aspectos organizativos, metodológicos de las clases y otros comentarios que quisieran hacer (ver Tabla 2). 
Tabla 2. Preguntas de los dos cuestionarios empleados ( $\mathrm{n}^{\circ} 12$ : Educación Familiar en la Infancia; n¹6: Modelos de Orientación en Psicopedagogía Familiar)

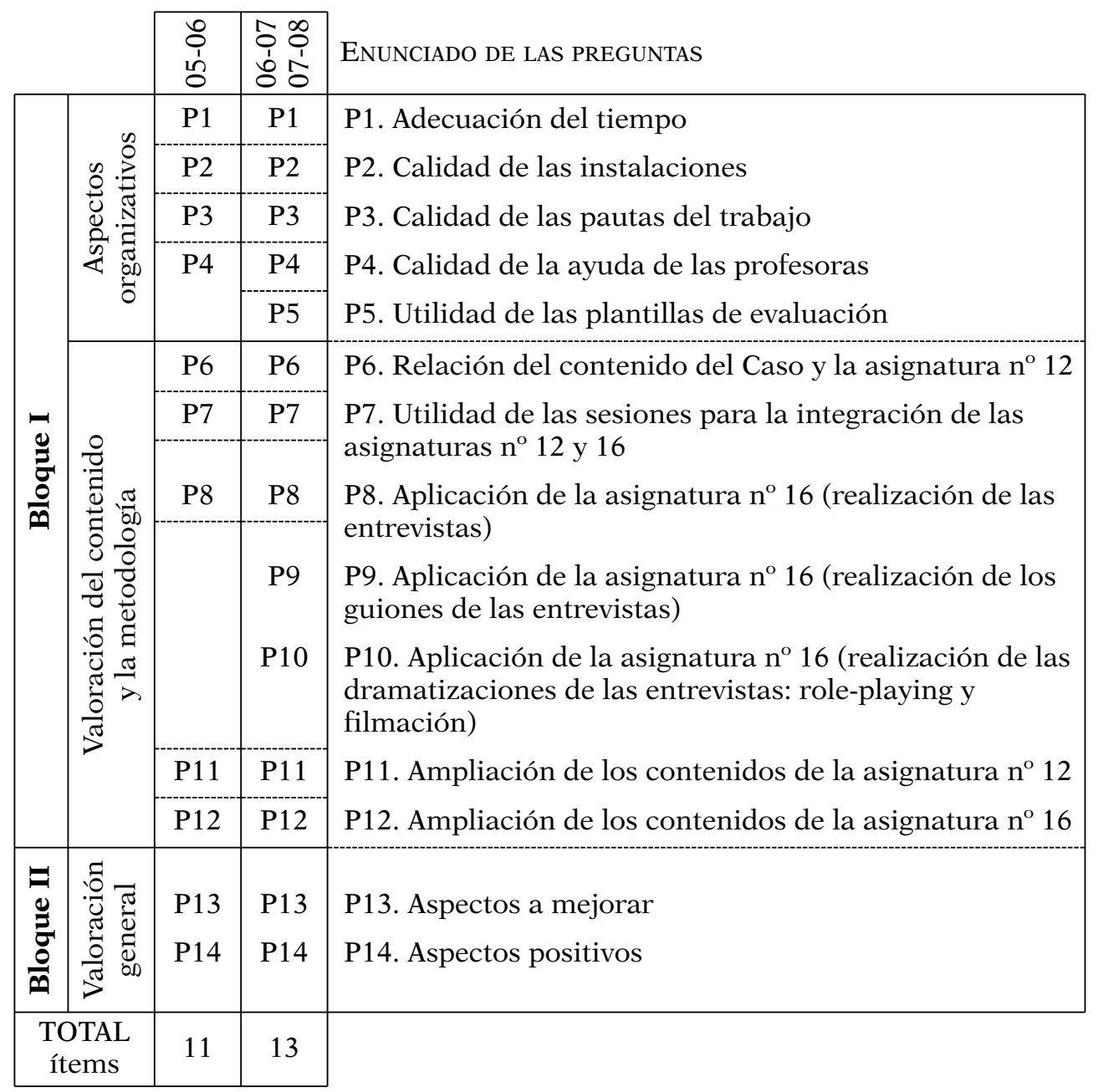

En el curso 05-06 se empleó un primer cuestionario compuesto por 11 preguntas. El primer bloque contó con nueve ítems en una escala de cinco puntos (1. Muy en desacuerdo; 2. En desacuerdo; 3. Neutro; 4. De acuerdo; y 5. Muy de acuerdo) que versaba sobre aspectos organizativos y metodológicos. La fiabilidad de este bloque del cuestionario (Alfa de Cronbach) fue de 0,88 . El segundo bloque con dos preguntas abiertas, cuestionaba aspectos positivos y mejorables de las profesoras y de las sesiones impartidas, dando también la oportunidad de apuntar cualquier otro comentario. 
En los cursos 06-07 y 07-08 se empleó el mismo cuestionario con algunas pequeñas modificaciones, se añadieron tres preguntas nuevas y se eliminó una, quedando por tanto un total 13 preguntas (ver Tabla 2). Se añadió una pregunta relativa a la utilidad de las Plantillas de evaluación que se habían introducido como novedad en esos cursos (pregunta 5), y otras dos preguntas nuevas (preguntas 9 y 10) en sustitución de la pregunta 8, para conocer en detalle la utilidad de la metodología empleada para realizar las entrevistas de orientación (en concreto, elaboración de los guiones y de la dramatización y filmación). La fiabilidad de este bloque del cuestionario (Alfa de Cronbach) fue de 0,79.

\section{RESULTADOS OBTENIDOS}

Si bien se ha aplicado esta metodología durante cinco cursos académicos, no ha sido hasta estos tres últimos cuando se han recogido de forma sistematizada las opiniones de los alumnos. A continuación se presentan las opiniones de 87 alumnos: 26 alumnos en el curso 2005-2006, 36 alumnos en el curso 2006-2007, y 25 alumnos en el curso 2007-2008. Los datos obtenidos en el primer bloque del cuestionario han sido tratados con el programa SPSS 15.0, y las respuestas abiertas recogidas en el segundo bloque, se han analizado agrupándolas por categorías y ofreciendo la frecuencia y tantos por cien. A continuación se describen los datos obtenidos en el primer y segundo bloque.

\subsection{Primer bloque}

\subsubsection{Aspectos generales y organizativos}

En una primera aproximación nos gustaría valorar los datos teniendo en cuenta de forma conjunta las opiniones de los alumnos de los tres cursos académicos. Observando los principales estadísticos descriptivos (ver Tabla 3) puede hacerse las siguientes apreciaciones:

- Todas las preguntas, que están medidas en una escala de cinco puntos, tienen una valoración igual o superior al 4 "De acuerdo".

- La adecuación del tiempo para realizar las entrevistas de orientación parece "Suficiente" (media 3,21), siendo ésta la pregunta peor valorada del cuestionario.

- El aspecto mejor valorado ha sido recogido en la pregunta 4 (media 4,51) "Calidad de la ayuda de las profesoras" $y$ en la pregunta 7 "Uti- 
lidad de las sesiones para la integración de los contenidos de las dos asignaturas", con una valoración entre el "De acuerdo" y "Muy de acuerdo".

Valorando los resultados de cada curso académico vemos lo siguiente (ver Tabla 3, y Figura 1):

- La valoración que se hace sobre la "Adecuación del tiempo" (pregunta 1) parece disminuir a lo largo de los tres años, pasando de una media de 4,12 en el curso 05-06, a una de 3,06 en el curso 06-07 y, finalmente a 2,48 en el curso 07-08. Las diferencias de estas medias son significativas únicamente en los cursos 05-06 y 06-07 $(\mathrm{F}=4,81, \mathrm{p}<0.05)$. Es curiosa esta percepción de los alumnos a lo largo del tiempo, ya que se ha aumentado el número de horas dedicadas al trabajo a lo largo de los tres cursos. Las razones para estas diferencias pueden ser muy variadas: el carácter más perfeccionista y trabajador de unos cursos frente a otros, o la inclusión de las plantillas de evaluación que ayudan a los alumnos a ser más conscientes de lo que se espera de ellos y por tanto, del trabajo que deben realizar.

- El resto de las preguntas de este apartado del cuestionario muestran algunas diferencias entre los cursos aunque no son significativas.

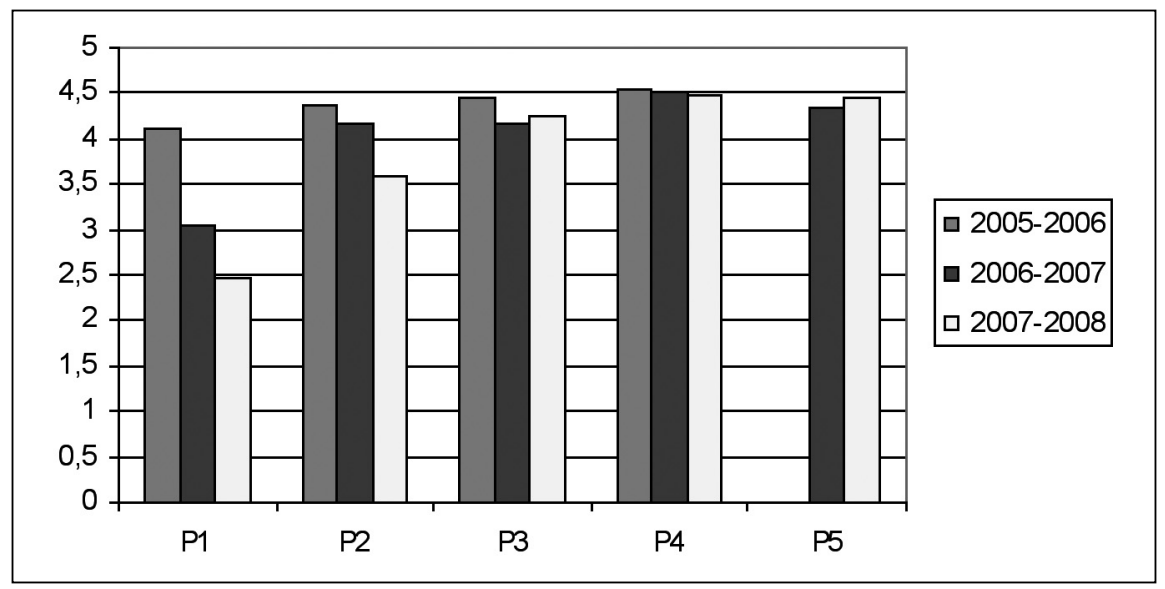

Figura 1. Medias de preguntas sobre Aspectos Organizativos 


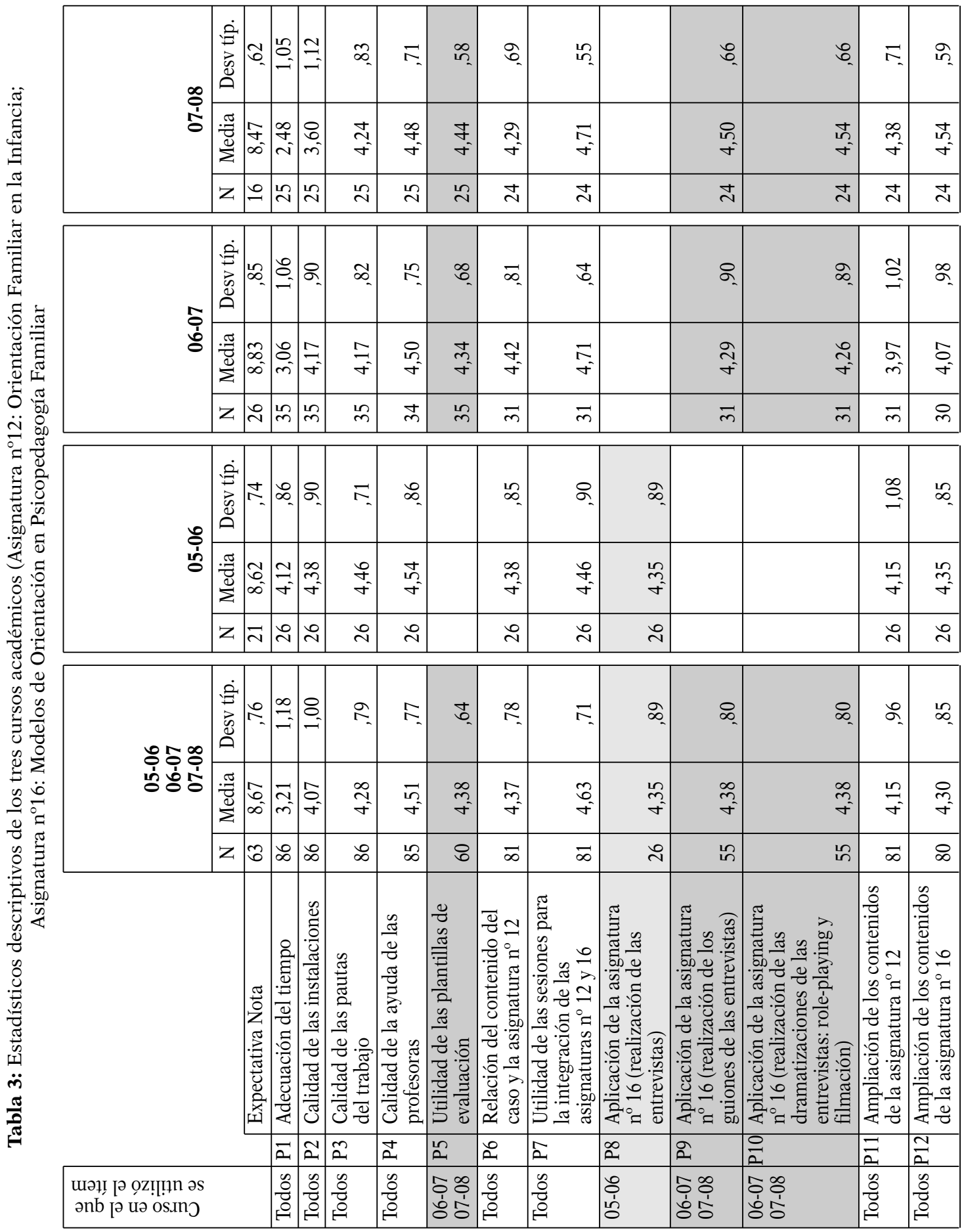




\subsubsection{Valoración del contenido y la metodología}

Haciendo una valoración global de los datos de los tres cursos podemos afirmar que (ver Tabla 3):

- Todas las preguntas, que están medidas en una escala de cinco puntos, tienen una valoración igual o superior al 4 "De acuerdo".

- El aspecto mejor valorado ha sido el recogido en la preguntas 7 (media 4,63), "Utilidad de las sesiones para la integración de los contenidos de las dos asignaturas", con una valoración entre el "De acuerdo" y "Muy de acuerdo".

- La valoración que se hace de las estrategias empleadas para elaborar las entrevistas de orientación es similar (media 4,3), tanto si se pregunta de forma genérica como se hizo en el curso 05-06 (pregunta 8: Aplicación de la asignatura $n^{\circ} 16$. Realización de las entrevistas) como si se pregunta específicamente, como se hizo en los cursos 06-07 y 07-08 (pregunta 9: Aplicación de la asignatura $n^{\circ}$ 16. Realización de los guiones de las entrevistas y pregunta 10: Aplicación de la asignatura $n^{\circ} 16$. Realización de las dramatizaciones de las entrevistas: Role-playing y filmación).

- Se aprecia una pequeña diferencia entre la valoración que hacen los alumnos sobre la utilidad de las sesiones para ampliar los contenidos de las dos asignaturas (pregunta 11: media 4,15 y pregunta 12: media 4,30), a favor de la asignatura más metodológica. Tiene sentido que los alumnos valoren mejor las sesiones prácticas a favor de la asignatura metodológica (pregunta 12) frente a la teórica (pregunta 11) ya que el objetivo final de las sesiones es precisamente afianzar unas competencias profesionales que exigen una práctica que no han tenido durante el curso.

Valorando los resultados de cada curso académico vemos que existen algunas diferencias en algunas preguntas (ver Tabla 3 y Figura 2):

- En el caso de la pregunta 7 "Utilidad de las sesiones para la integración de las dos asignaturas", aumenta la valoración positiva de los alumnos desde el curso 05-06 (media de 4,46) a los cursos 06-07 y 07-08 (media alrededor del 4,7), siendo ésta significativa $(\mathrm{F}=4,29$, $\mathrm{p}<.05$ ). Quizás la experiencia acumulada de los años de las profesoras o bien la inclusión de las plantillas de evaluación, han hecho que la integración de los objetivos perseguidos en ambas asignaturas se integren de un modo más coherente y claro para el alumnado. 


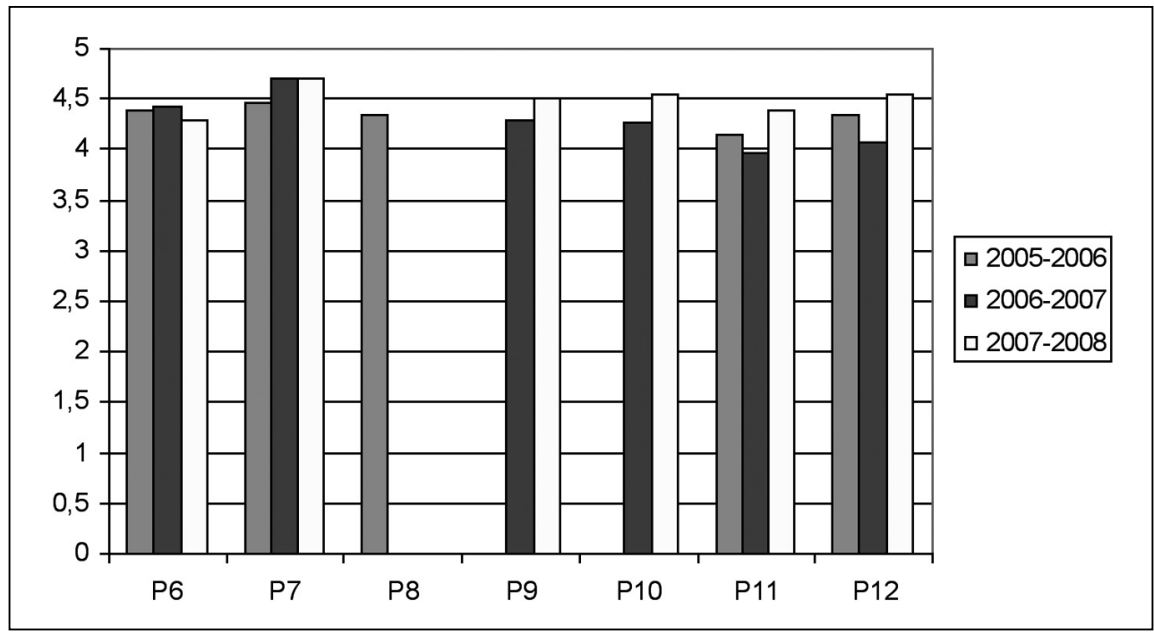

Figura 2. Medias de las preguntas sobre Valoración del contenido y la metodología

- En el caso de las preguntas 9 y 10 introducidas en los cursos 06-07 y 07-08 sobre la valoración de la metodología empleada para elaborar las entrevistas (Realización de guiones de las entrevistas y Realización de las dramatizaciones de las entrevistas: role-playing y filmación respectivamente) se ve un aumento de la valoración de una media de 4,2 en el 06-07 a 4,5 en el 07-08, que podría ser achacable a la introducción de las Plantillas de evaluación (pregunta $\mathrm{n}^{\circ}$ 5), pero dichas diferencias no son significativas.

\subsubsection{Correlaciones}

Respecto a las relaciones existentes entre las preguntas del cuestionario, encontramos que las correlaciones de Pearson son significativas $(\mathrm{p}<.01)$ en los siguientes casos:

El ítem 5 "Utilidad de las plantillas de evaluación" correlaciona con el ítem 3 "Calidad de las pautas del trabajo" $(0,63)$ y con el ítem 7 "Utilidad de las sesiones para la integración de las asignaturas no 12 y 16" $(0,48)$.

Además, el ítem 3 "Calidad de las pautas del trabajo" correlaciona con el ítem 4 "Calidad de la ayuda de las profesoras" $(0,47)$. 


\subsection{Segundo bloque: aspectos positivos y mejorables}

En el segundo bloque del cuestionario se preguntaba por aquellos aspectos positivos y mejorables a través de preguntas abiertas. La idea fue ofrecer la oportunidad a los alumnos para que añadieran o señalaran algún aspecto no recogido en las preguntas anteriores. La incidencia de las respuestas a estas preguntas fue muy desigual a lo largo de los cursos. En la tabla 4 puede verse el tanto por cien de las respuestas recogidas con estas preguntas. Por todo ello, las valoraciones que se mencionan a continuación corresponden a las respuestas recogidas por los que contestan, y por tanto, no son del todo representativas de las opiniones de la totalidad del grupo (Ver Tablas 4, 5 y 6).

Tabla 4. Frecuencias y tantos por ciento totales de las respuestas al segundo bloque

\begin{tabular}{|l|c|c|c|c|c|c|}
\hline & \multicolumn{2}{|c|}{$\mathbf{0 5 / 0 6}$} & \multicolumn{2}{|c|}{$\mathbf{0 6 / 0 7}$} & \multicolumn{2}{c|}{$\mathbf{0 7 / 0 8}$} \\
\hline & $\mathbf{f r}$ & $\%$ & $\mathbf{f r}$ & $\%$ & $\mathbf{f r}$ & $\%$ \\
\hline $\mathrm{N}^{\circ}$ de alumnos por curso & 26 & 100 & 36 & 100 & 25 & 100 \\
\hline Respuestas a los aspectos positivos & 19 & 52 & 13 & 59.1 & 21 & 84 \\
\hline Respuestas a los aspectos mejorables & 2 & 10.5 & 9 & 40 & 6 & 24 \\
\hline
\end{tabular}

Tabla 5. Aspectos positivos: frecuencia y tanto por ciento de las respuestas de los alumnos

\begin{tabular}{|l|c|c|c|c|c|c|}
\hline \multirow{2}{*}{ CURSO } & \multicolumn{2}{|c|}{$\mathbf{0 5 / 0 6}$} & \multicolumn{2}{c|}{$\mathbf{0 6 / 0 7}$} & \multicolumn{2}{c|}{$\mathbf{0 7 / 0 8}$} \\
\cline { 2 - 8 } & $\mathbf{f r}$ & $\%$ & $\mathbf{f r}$ & $\%$ & $\mathbf{f r}$ & $\%$ \\
\hline Personalidad & 3 & 15.8 & 3 & 23.1 & 4 & 19 \\
\hline Preparación docente & 3 & 15.8 & 1 & 7.7 & 4 & 19 \\
\hline $\begin{array}{l}\text { Clima de aula: distendido, dinámico, } \\
\text { trabajo grupal }\end{array}$ & 5 & 26.3 & & & & 19 \\
\hline Contenido de las sesiones & 2 & 10.5 & 1 & 7.7 & 2 & 9.5 \\
\hline Todo correcto & 6 & 31.6 & 8 & 61.5 & 7 & 33.3 \\
\hline
\end{tabular}


Tabla 6. Aspectos mejorables: frecuencia y tanto por ciento de las respuestas de los alumnos

\begin{tabular}{|l|c|c|c|c|c|c|}
\hline \multirow{2}{*}{ CURSO } & \multicolumn{2}{|c|}{$\mathbf{0 5 / 0 6}$} & \multicolumn{2}{c|}{$06 / 07$} & \multicolumn{2}{c|}{$07 / 08$} \\
\cline { 2 - 8 } & $\mathbf{f r}$ & $\%$ & $\mathbf{f r}$ & $\%$ & $\mathbf{f r}$ & $\%$ \\
\hline Adecuación del tiempo: filmación & 1 & 50 & 1 & 11.1 & 1 & 16.7 \\
\hline $\begin{array}{l}\text { Adecuación del tiempo: valoración final } \\
\text { de los trabajos }\end{array}$ & 1 & 50 & & 11.1 & 2 & 33.3 \\
\hline $\begin{array}{l}\text { Inadecuación de los medios técnicos } \\
\text { disponibles }\end{array}$ & & & & & & 16.7 \\
\hline Evaluación interpares & & & 1 & 11.1 & & \\
\hline $\begin{array}{l}\text { Distribución diferente en el calendario } \\
\text { general de las sesiones presenciales }\end{array}$ & & & & 66.6 & & 33.3 \\
\hline
\end{tabular}

Para informar sobre estos aspectos, se seguirá la diferenciación entre variables estáticas y variables dinámicas (Aguado, 1993; Arias y cols., 1995; Torroba, 1993). Se considera estática la variable que una vez definida, persiste hasta el final de la ejecución del programa. Y será dinámica aquella variable que puede verse modificada durante la ejecución del programa. Así, mientras que las variables estáticas se refieren al entorno material donde se desarrollan las sesiones teóricas y prácticas de las clases, la distribución del tiempo, las instalaciones, los recursos, equipamiento con los que se cuenta o el contenido; las variables dinámicas hacen alusión a los aspectos relacionados con quienes llevan a cabo las sesiones presenciales, en concreto, al equipo docente: personalidad de las profesoras y preparación docente, el clima en el que se desarrollan las sesiones y la metodología empleada (Ver tabla 7).

Tabla 7. Especificación de variables estáticas y dinámicas

\begin{tabular}{ll}
\hline & Entorno material \\
Variables estáticas & Cantidad y distribución de tiempo \\
& Instalaciones \\
& Recursos, equipamientos \\
& Contenido \\
\hline & Personalidad de las profesoras \\
& Preparación docente \\
Variables dinámicas & Profesionalidad \\
& Clima del aula \\
& Metodología empleada \\
\hline
\end{tabular}


A continuación se realizará una valoración global de los datos de los tres cursos académicos.

\subsubsection{Aspectos positivos}

- En los tres cursos se coincide en señalar como positivas la personalidad de las profesoras, en mayor medida en el curso 06/07, y la preparación docente destacada sobre todo en el curso 07/08. Se especifica la buena disposición a la hora de llevar a cabo la sesión práctica, la cercanía, la amabilidad, la motivación, la ayuda recibida y la atención a los detalles, la profesionalidad a la hora de impartir las sesiones y la cercanía de las docentes a la hora de enseñar y de asesorar a los grupos.

- La valoración que se hace del clima del aula en el que se desarrollan las sesiones, es considerado positivo en los cursos 05/06 y 06/07 al definirse como distendido y dinámico. Por su satisfacción, algún alumno llega a sugerir que se extienda esta metodología a otras asignaturas del master.

- La variable estática contenido de las sesiones, es valorada positivamente por su utilidad y aplicabilidad en los tres cursos de forma parecida.

- Es destacable la valoración global positiva que realizan los alumnos en los tres cursos, especialmente destacado en el curso 06/07.

\subsubsection{Aspectos mejorables}

- Como puede apreciarse en la tabla 4, la incidencia de las respuestas a esta pregunta ha sido muy baja. No obstante, se puede mencionar la unanimidad que hay en las opiniones de los alumnos de los tres cursos en considerar la variable estática tiempo como aspecto mejorable. En concreto se señala:

- La cantidad de tiempo prevista para la filmación fue valorada como interesante, pero escasa e insuficiente.

- En los tres cursos se apuntó que la cantidad de tiempo asignado para establecer un diálogo final conclusivo resultó escaso, si bien esta variable fue considerada como adecuada y suficiente por el resto del alumnado (Ver Figura 1). 
- Se considera también mejorable la distribución del tiempo de la asignatura impartida en relación con las demás que se imparten en el presencial del Master. En concreto, los alumnos apuntan su preferencia por tener la docencia de estas dos asignaturas al principio del presencial, y no al final del mismo, por lo que supone de inversión en trabajo y el esfuerzo en un momento en el que ya están demasiado cansados. Debe tenerse en cuenta que los alumnos proceden de países de todo el mundo, con el consiguiente cansancio por el viaje y el cambio de horario que les supone asistir al presencial.

- La evaluación interpares introducida fue valorada en bajo porcentaje como una medida incómoda para los compañeros del grupo en el curso 06/07 y 07/08.

\subsubsection{A modo de resumen}

Los resultados obtenidos en esta parte del cuestionario no hacen más que apoyar algunas de las conclusiones obtenidos en la primera parte respecto a la alta valoración que hacen los alumnos de las profesoras, en cuanto a la ayuda ofrecida y su preparación, y la valoración de la metodología empleada. En cambio en relación con la variable tiempo, los resultados de la primera parte del cuestionario hacen pensar que ha sido suficiente, sin embargo algunas de las respuestas dadas en esta parte del cuestionario apuntan, en concreto, a una falta de tiempo para filmar las entrevistas.

\section{CONCLUSIONES}

En este artículo se ha querido mostrar la experiencia de renovación metodológica llevada a cabo a nivel de postgrado para fomentar una enseñanza centrada en el alumno que desarrollara a su vez una serie de competencias. En concreto, la peculiaridad de la experiencia mostrada radica en que forma parte de un Master de modalidad on-line que combina unas sesiones presenciales al finalizar la docencia del curso para poner en práctica los contenidos estudiados a lo largo del curso académico.

En estas sesiones presenciales pretendíamos (y seguimos en ello) integrar la docencia de dos asignaturas del master de carácter teórico y práctico a través del método del caso, la dramatización o role-playing, el uso del vídeo digital y el apoyo de plantillas de evaluación o rubrics.

Los datos recogidos sobre las valoraciones hechas por los alumnos durante tres cursos académicos nos hacen afirmar que: 
1. Los alumnos perciben como valiosa y enriquecedora la metodología empleada:

a. Les ha ayudado a integrar los contenidos de las dos materias (ítem 7). Esta valoración positiva aumenta a lo largo de los tres cursos académicos, correlacionando significativamente con el ítem 5 "Utilidad de las plantillas de evaluación”.

b. Valoración muy positiva de la elaboración de los guiones de las entrevistas y de las dramatizaciones (ítems 8, 9 y 19). Esta valoración también se ve aumentada en los dos últimos cursos académicos, coincidiendo con la introducción de las plantillas de evaluación.

c. Ven deseable que la metodología empleada se amplíe en las sesiones presenciales de las otras materias del master.

D. Perciben un buen clima en el aula al fomentar un ambiente distendido y de trabajo grupal.

e. La adecuación del tiempo empleado (ítem 1 y 13), a lo largo de las sesiones para realizar el trabajo de los grupos, ha sido la variable menos valorada. En concreto, se considera "suficiente" incluso unos pocos alumnos mencionan que ha sido insuficiente. Se aprecia una valoración cada vez menor de este ítem a lo largo de los tres cursos. Este dato es llamativo ya que en los dos últimos años se aumentó el tiempo dedicado, apuntamos una posible explicación: la combinación del hecho de que los grupos cada vez han sido más exigentes, trabajadores e implicados en la tarea, y que la introducción de las plantillas de evaluación pudo ayudar a los alumnos a ser más conscientes de la complejidad del trabajo que debían realizar.

f. En el curso 07-08 debido a problemas técnicos, unos pocos alumnos valoran negativamente la adecuación de las instalaciones, aunque esta percepción no influyó negativamente en la valoración positiva que hacen de la metodología empleada.

2. Los alumnos valoran positivamente las pautas o andamios que se les ofrecen a través de varios medios. En concreto, valoran muy positivamente la calidad de las pautas ofrecidas (ítem 3), la ayuda y atención recibida de las profesoras a lo largo de las sesiones (ítem 4 y 14), y las plantillas de evaluación (ítem 5). Además se ve como estas preguntas están relacionadas entre sí al ofrecer correlaciones significativas (ver apto. 4.1.3). 
De nuestra experiencia como docentes durante estos años, y a la luz de las opiniones de nuestros alumnos podemos concluir que el uso del vídeo digital ha sido un elemento motivador que ha ayudado a implicar a los alumnos en los trabajos desarrollados en los pequeños grupos. El hecho de mostrar a los demás lo realizado, y por tanto hacerlo público, parece un buen aliciente para realizar buenos trabajos. No obstante, hay que tener en cuenta que los pequeños problemas técnicos que pueden surgir provocan una cierta frustración y nerviosismo en los alumnos. Quizá una alternativa para solucionar estos problemas en próximos cursos, sea contar con una única cámara y hacerla rotar entre los diversos grupos, y así de este modo evitar los problemas de formatos y sistemas compatibles europeos-americanos.

Asimismo, cabe considerar que para fomentar el aprendizaje centrado en el alumno es necesario emplear estrategias didácticas activas como en nuestra experiencia han sido el método del caso, el role-playing y el trabajo cooperativo. Pero además, es fundamental ofrecer los medios necesarios para que los alumnos puedan desenvolverse con autonomía y al mismo tiempo ofrecerles guías y estructura. Nuestra experiencia y las correlaciones obtenidas (ver apto. 4.1.3), nos dicen que es deseable la introducción de guías o andamios a lo largo de las actividades que se proponen a los alumnos. En nuestra propuesta metodológica estas guías adoptaron varias formas: guías y explicaciones verbales, explicaciones y pautas del trabajo a realizar en papel, empleo de roles para distribuir tareas en el trabajo que había que realizar, plantillas para realizar las entrevistas, plantillas de evaluación, y un constante asesoramiento de la actividad de los grupos. 


\begin{tabular}{|c|c|c|c|c|}
\hline & $\frac{8}{\frac{8}{5}}$ & & & \\
\hline & $\begin{array}{l}0 \\
: 3 \\
\end{array}$ & & & \\
\hline & 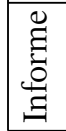 & & & \\
\hline & & 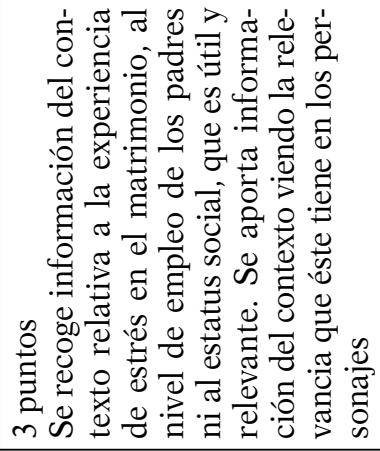 & 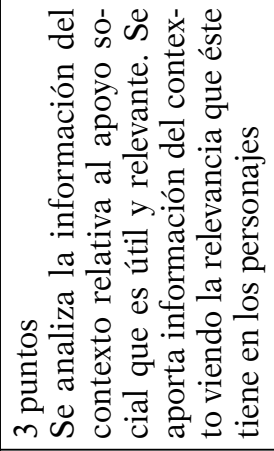 & 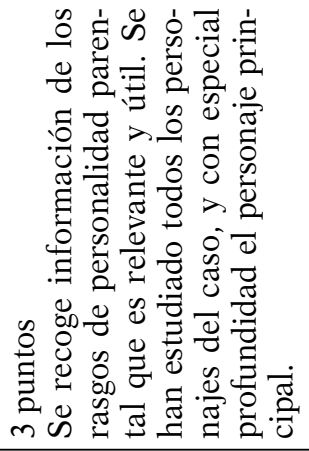 \\
\hline 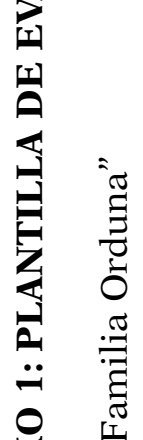 & & 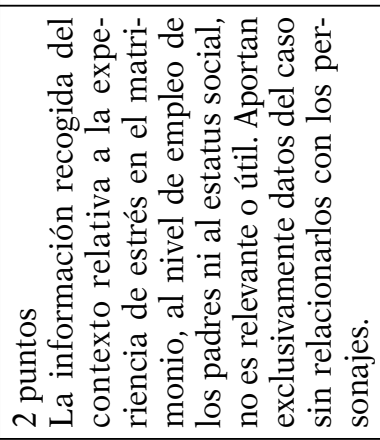 & 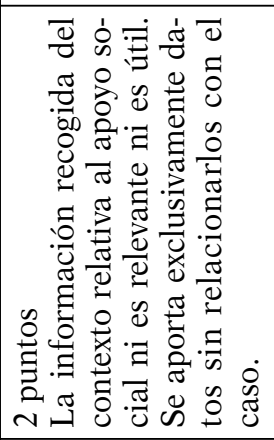 & 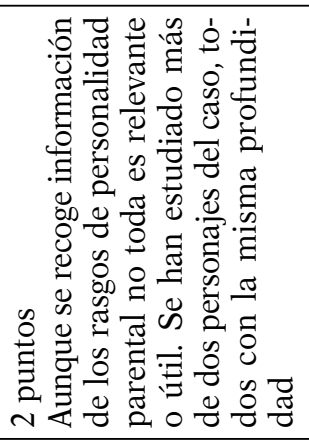 \\
\hline 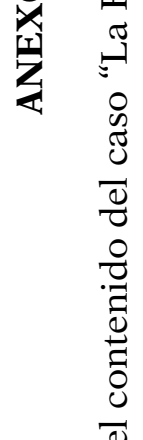 & 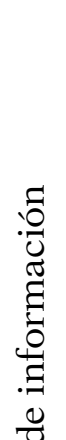 & 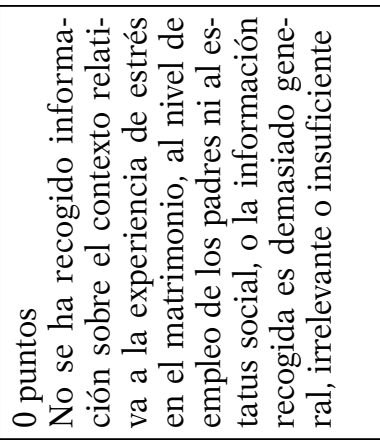 & 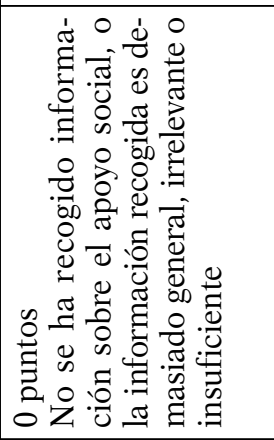 & 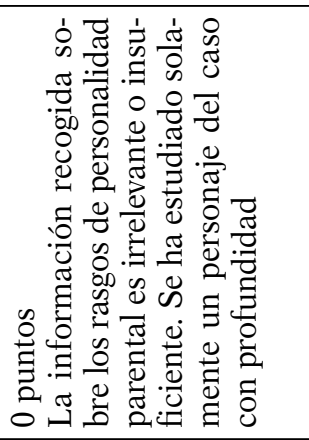 \\
\hline 党 & 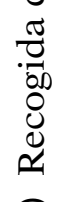 & 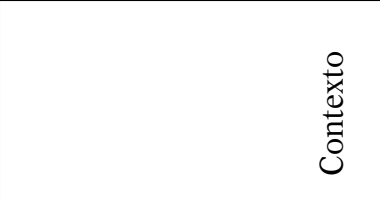 & & 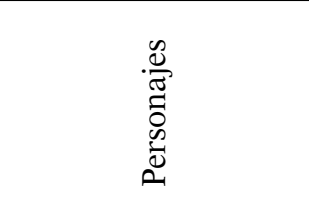 \\
\hline & శิ & & & \\
\hline
\end{tabular}




\begin{tabular}{|c|c|c|c|c|}
\hline$\frac{8}{\frac{8}{V}}$ & & & & \\
\hline 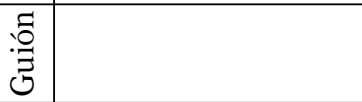 & & & & \\
\hline$\tilde{\Xi}$ & & & & \\
\hline 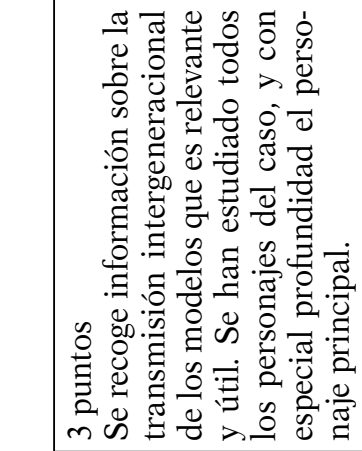 & 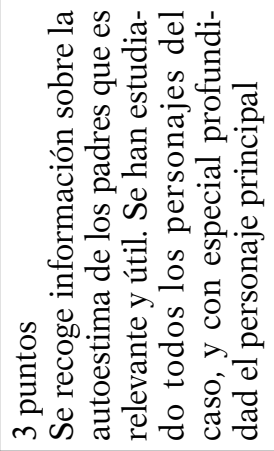 & 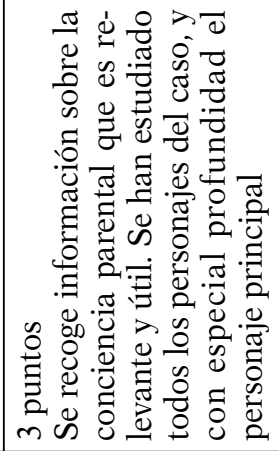 & 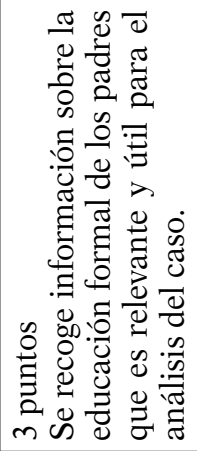 & 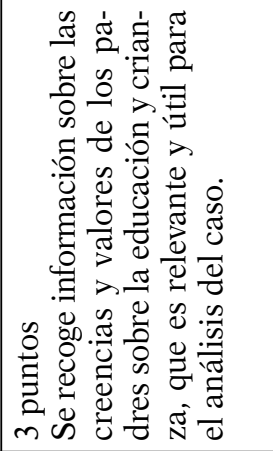 \\
\hline 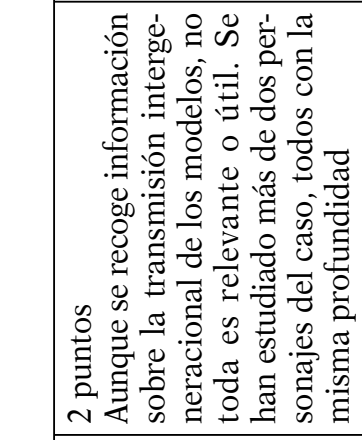 & 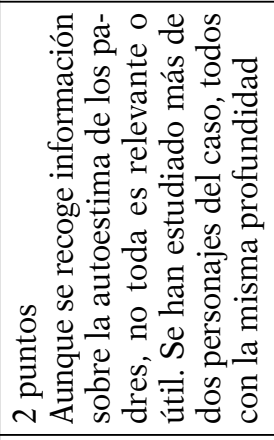 & 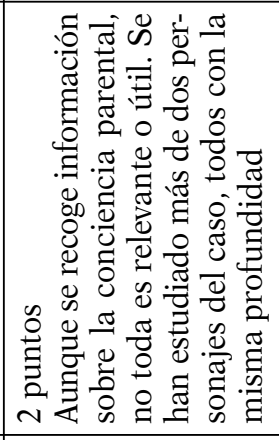 & 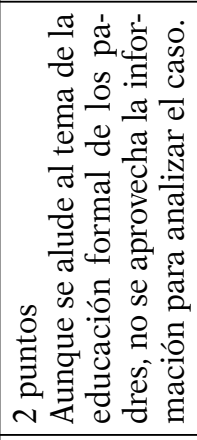 & 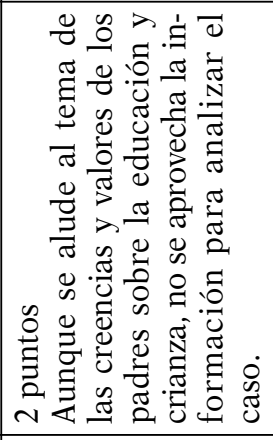 \\
\hline 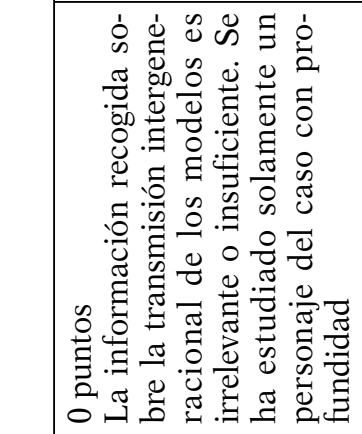 & 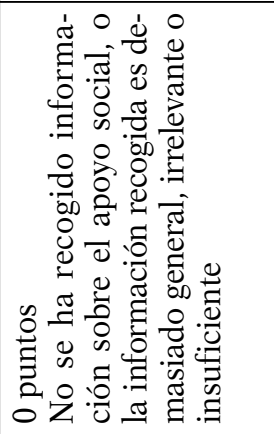 & 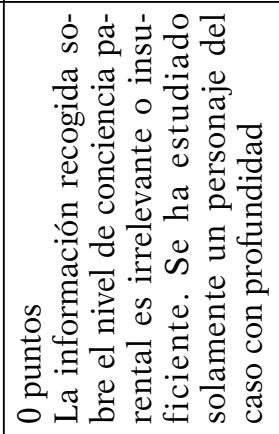 & 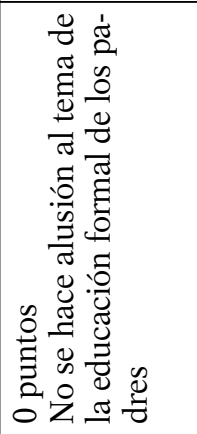 & 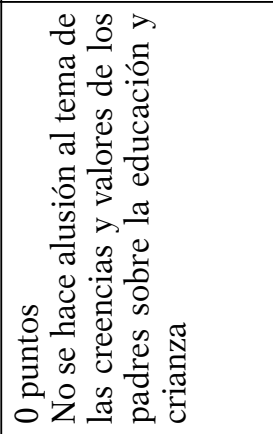 \\
\hline & & 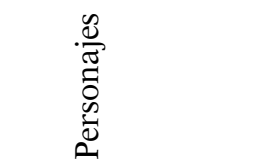 & & \\
\hline
\end{tabular}




\begin{tabular}{|c|c|c|c|c|}
\hline$\frac{8}{\frac{8}{5}}$ & & & & \\
\hline 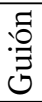 & & & & \\
\hline 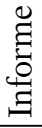 & & & & \\
\hline & 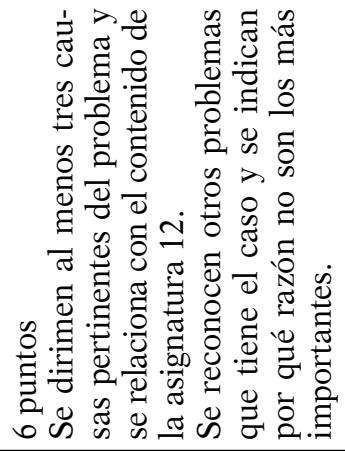 & 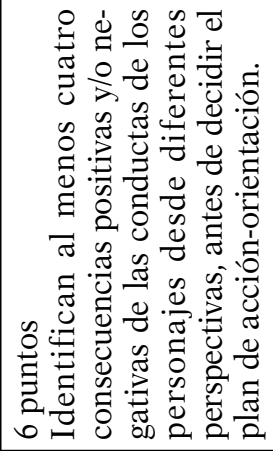 & 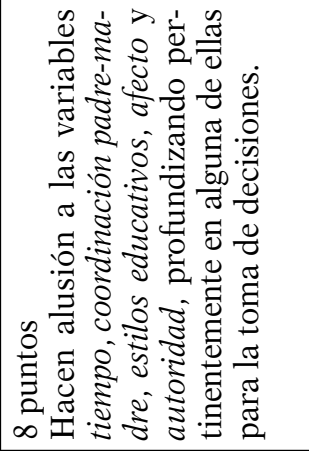 & 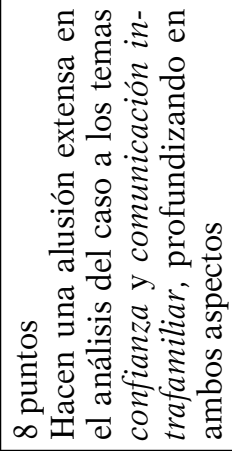 \\
\hline & 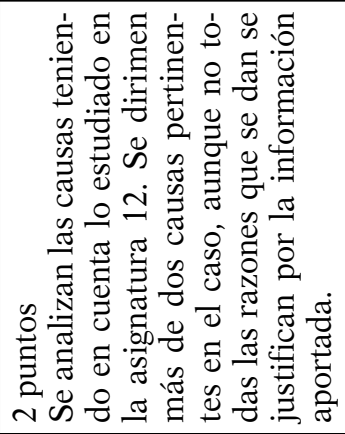 & 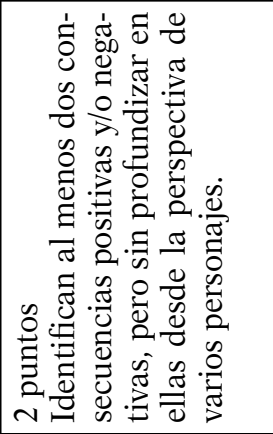 & 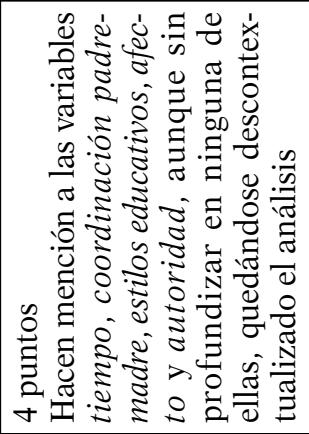 & 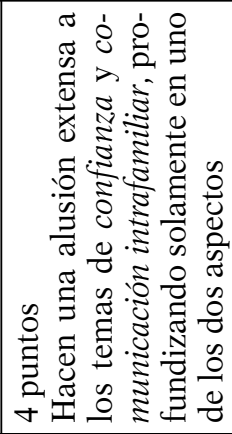 \\
\hline & 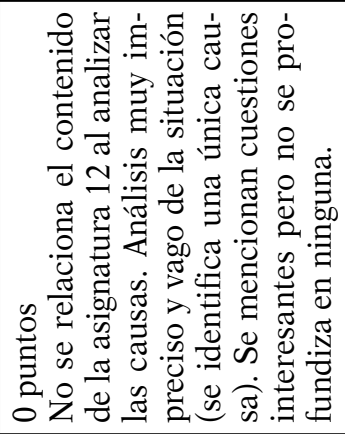 & 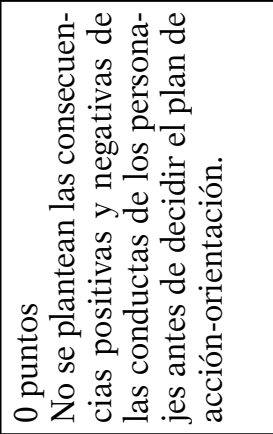 & 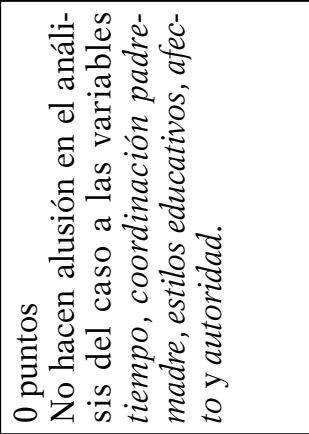 & 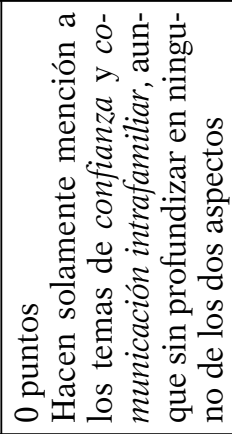 \\
\hline & 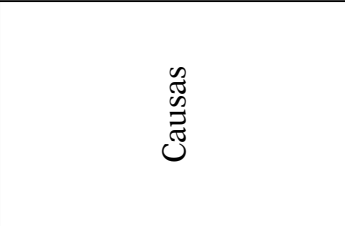 & 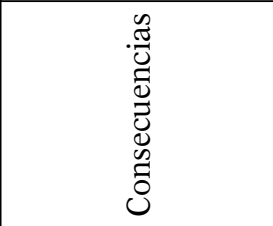 & 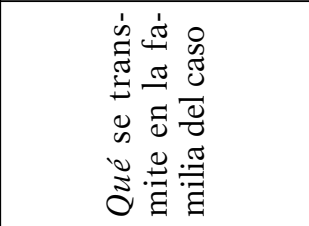 & 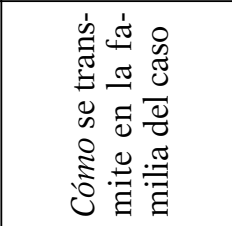 \\
\hline
\end{tabular}




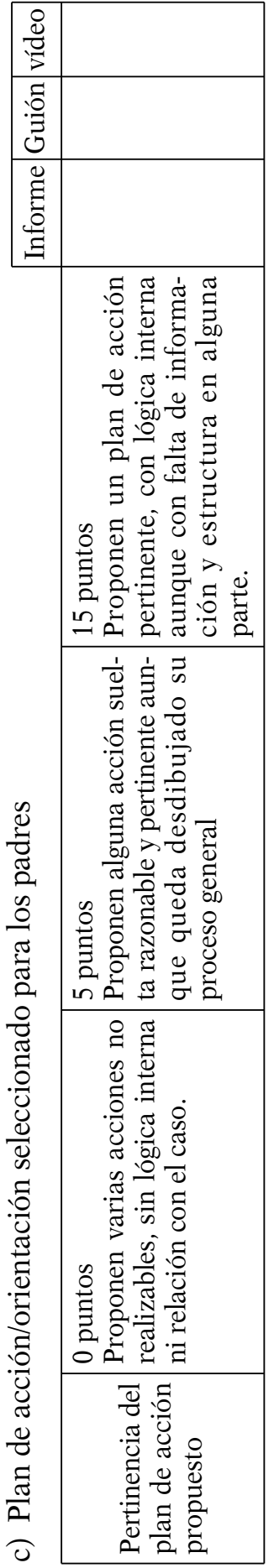

\begin{tabular}{|c|c|c|c|c|}
\hline 8 & & & & \\
\hline בְ & & & & \\
\hline & 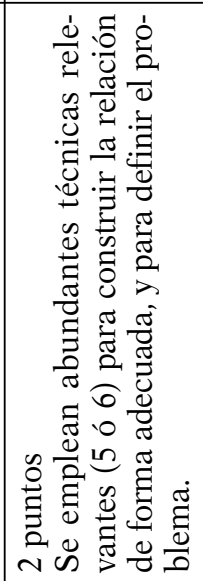 & 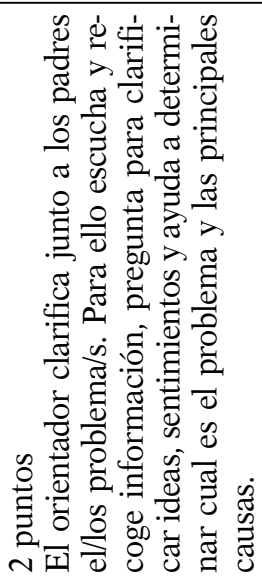 & 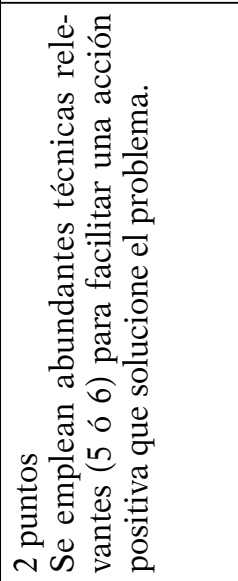 & 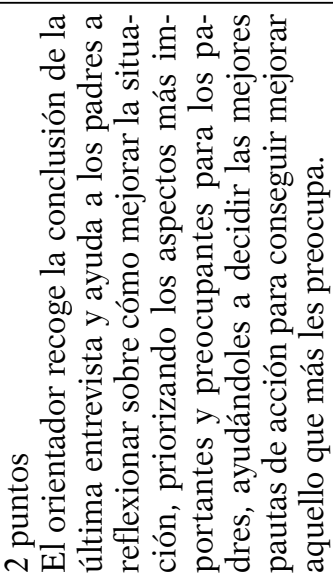 \\
\hline $\begin{array}{l}0 \\
0 \\
0 \\
\mathbb{8} \\
0 \\
0 \\
0 \\
0 \\
0 \\
0\end{array}$ & 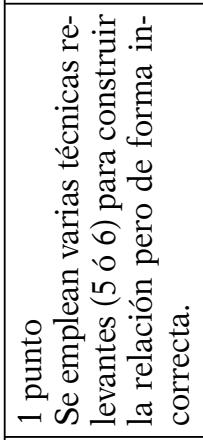 & & 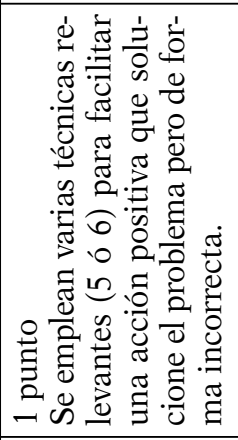 & \\
\hline$\stackrel{\pi}{\infty}$ & 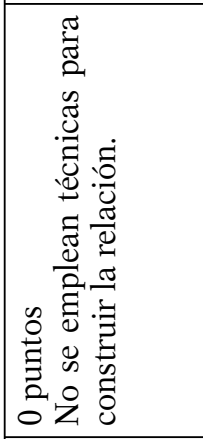 & & 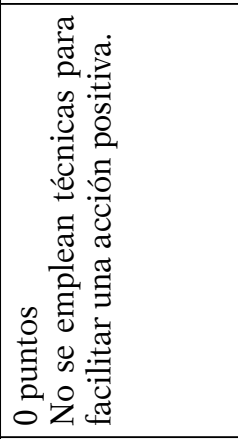 & \\
\hline$\tau$ & 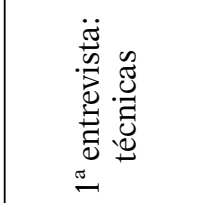 & 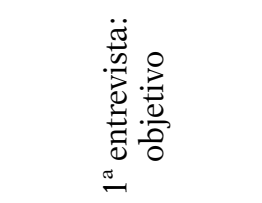 & 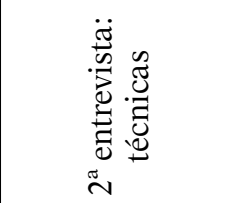 & 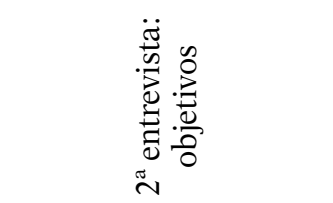 \\
\hline
\end{tabular}




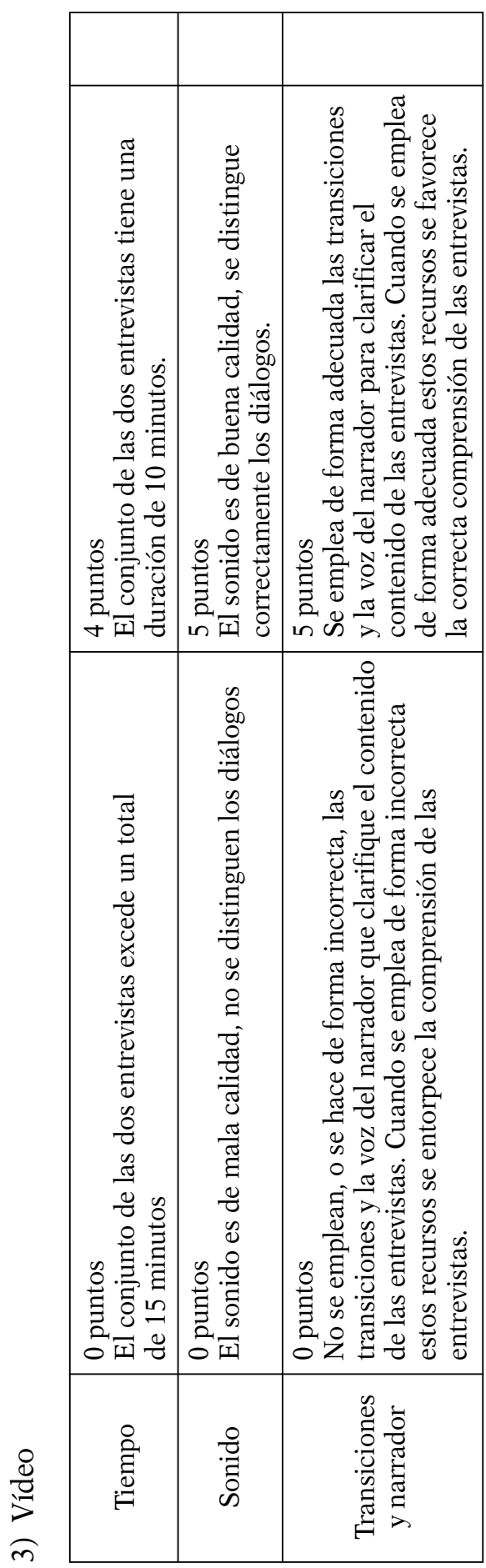




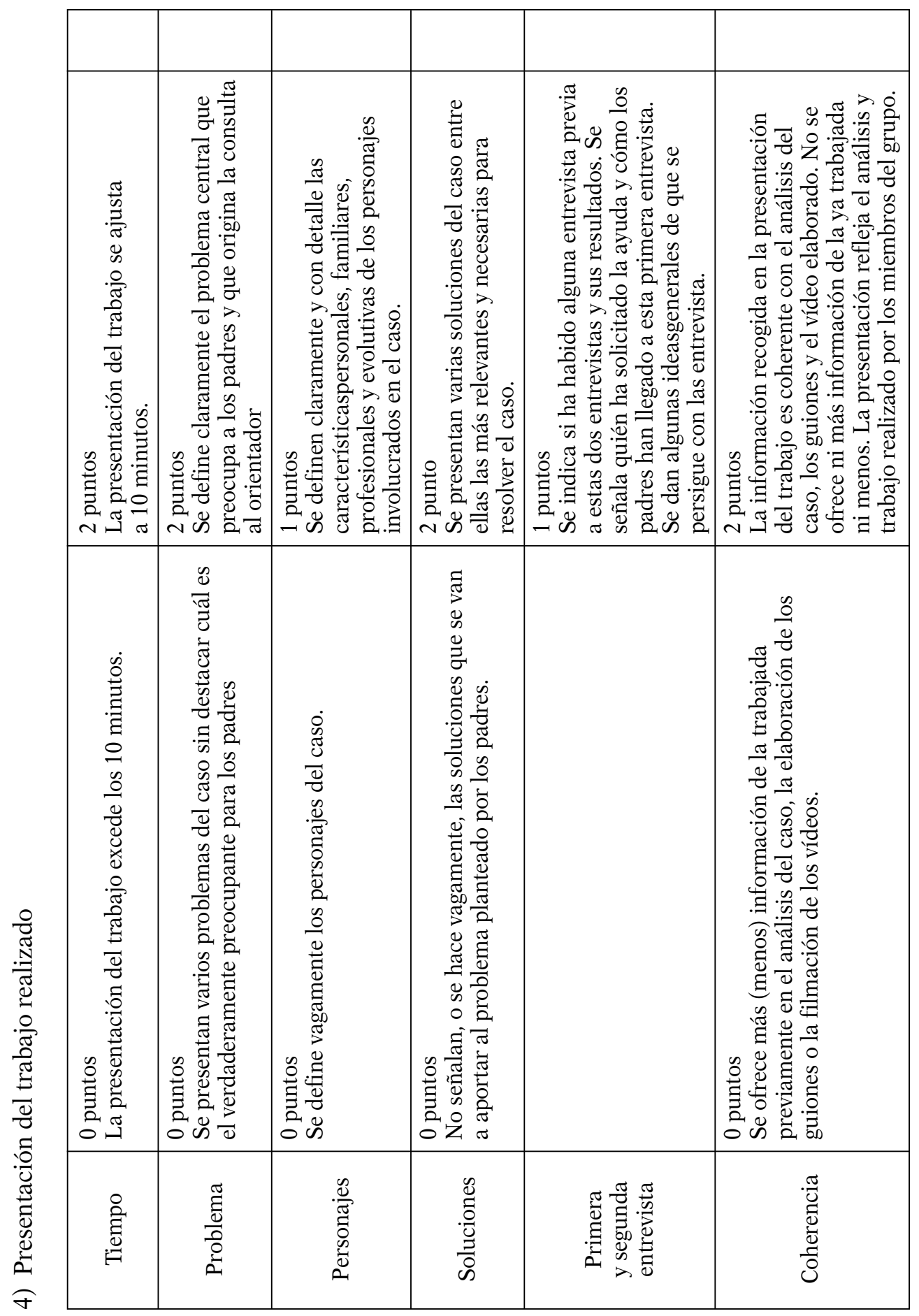




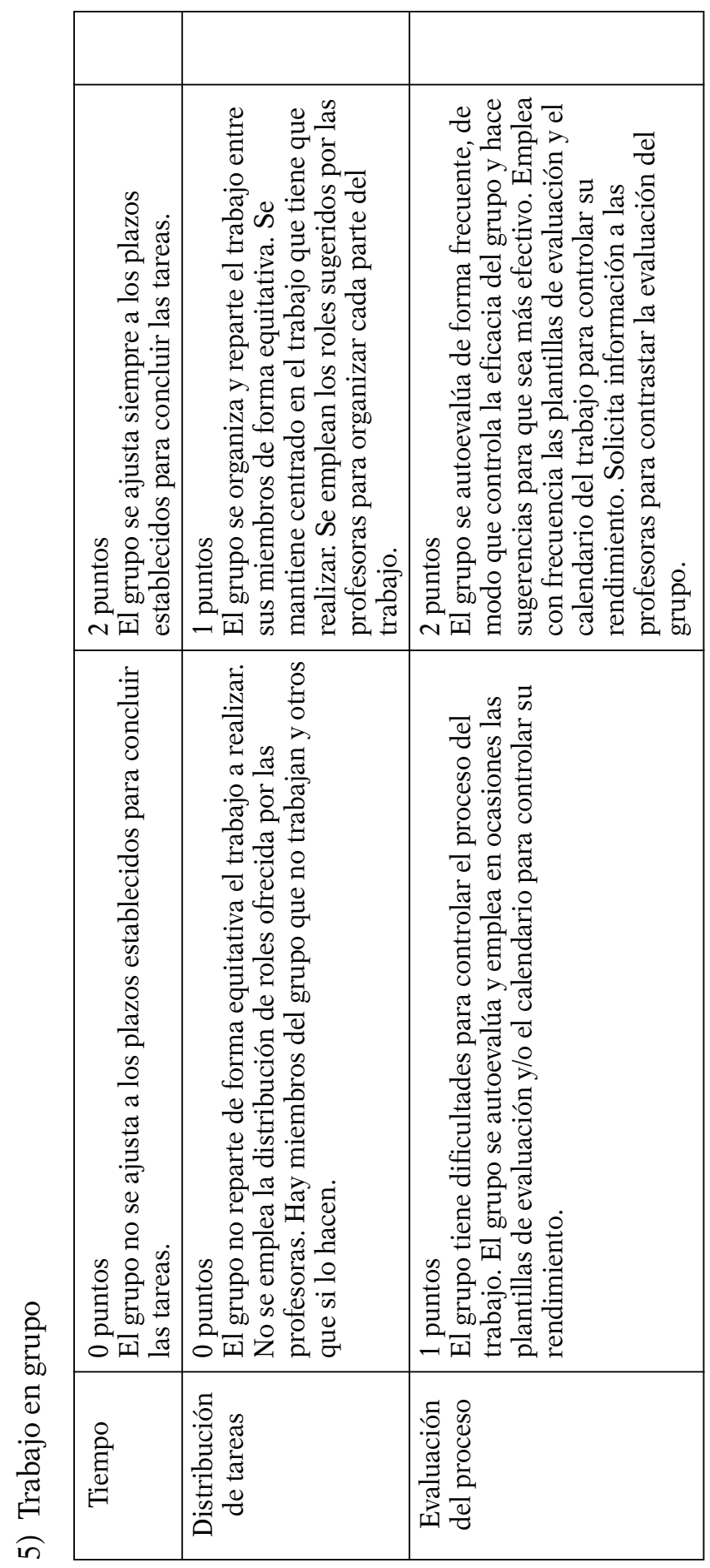




\section{NOTAS}

(1) Puede consultarse la página web de este Master para mayor información en $<$ http://www.unav.es/icf/master/> 


\section{REFERENCIAS BIBLIOGRÁFICAS}

Aguado, T. (1993). Análisis y evaluación de modelos y programas de educación infantil en el marco de la reforma de la enseñanza. Madrid: UNED.

Arias, B.; Verdugo, M. A.; Rubio, V. J. (1995). Evaluación de la actividad Modelo local de Valladolid. Programa Helios. Madrid: CIDE-MEC.

Beltrán, J. (1996). Concepto, desarrollo y tendencias actuales de la psicología de la instrucción. En Beltrán, J. y Genovard, C. (Ed.) Psicología de la Instrucción I. Variables y procesos. Madrid: Síntesis, 19-86.

Bransford, J. D.; Brown, A. L. y Cocking, R. R. (2001). How people learn. Brain, mind, experience, and school. Washington, D. C. National Academy Press.

Dembo, M. H. (2001). Learning to teach is not enough, future teacher also need to learn how to learn. Teacher Education Quarterly, 28(4), 23-35.

Chocarro, E. (2006). Formación del profesorado para el desarrollo del aprendizaje autorregulado en sus alumnos. Trabajo de investigación defendido en el Departamento de Educación de la Universidad de Navarra el 27 de Septiembre.

Chocarro, E.; González-Torres, M. C. y Sobrino, A. (2007). Nuevas orientaciones en la formación del profesorado para una enseñanza centrada en la promoción del aprendizaje autorregulado de los alumnos. Estudios Sobre Educación, 12, 81-98.
Johnson, D. W.; Johnson, R. T. y Holubec, E. J. (1994). El Aprendizaje Cooperativo en el aula. Buenos Aires: Paidós.

Lara, S.; Chocarro, E. y Sobrino, A. (2008). El andamiaje en el aprendizaje autorregulado: una experiencia con la WebQuest. En Roig Vila, R. (Coord.) Blasco, J.; Cano, M. A.; Gilar, R.; Grau, A. y Lledó, A. (Eds.) (2008). Investigación e innovación en el conocimiento educativo actual. Alcoy: Editorial Marfil, 229-242.

Lara, S. y Rivas, S. (2007). Calidad de la enseñanza en estudios de postgrado. Eficacia de la integración de las sesiones prácticas de dos asignaturas. Comunicación presentada en el Congreso Nacional de Métodos de Investigación Educativa, celebrado en San Sebastián los días 27 al 29 de Junio.

MEC (2005). Espacio europeo de Educación Superior (EEES). Madrid: MECConsejo de Coordinación Universitaria.

Torroba, I. (1993). Evaluación cualitativa de centros en el marco de la LOGSE. Bordón, 45 (3), 295-305.

Vélaz de Medrano, C. (2008). Formación y profesionalización de los orientadores desde el enfoque de competencias. Educación XX1, 11, 155-181.

Weimer, M. (2002). Learned-centered teaching: five keys changes to practice. San Francisco: Jossey Bass.

Zimmerman, B. J. (2002). Becoming a self-regulated learner: An overview. Theory into Practice, 41 (2), 64-70. 


\section{PALABRAS CLAVE}

Aprendizaje autorregulado, Enseñanza centrada en el alumno, Método del caso, Plantillas de evaluación o rúbricas, Vídeo digital, Competencias

\section{KEYWORDS}

Self-regulated learning, Learned- centered teaching, Case Method, Rubrics, Competences

\section{PERFIL ACADÉMICO DE LAS AUTORAS}

Sonia Lara, Profesora Contratada Doctora de Didáctica y Organización Escolar en la Universidad de Navarra. Ha realizado diversas estancias postdoctorales en centros universitarios extranjeros (Boston University y Nortwestern University). Ha participado en diversos proyectos de investigación sobre el uso de las Tecnologías de la Información y la Comunicación (TIC) tanto en la enseñanza media como universitaria, así como en proyectos de innovación educativa y formación del profesorado no universitario y universitario.

Sonia Rivas Borrell, Profesora Ayudante Doctor de la Facultad de Filosofía y Letras de la Universidad de Navarra, donde imparte dos asignaturas en la licenciatura de Pedagogía. Asimismo, es docente en el Master que organiza el Instituto de Ciencias para la Familia (ICF). Ha realizado diversas estancias postdoctorales en centros universitarios extranjeros. Autora de diversas comunicaciones y artículos sobre la familia y la mejora de la calidad de las intervenciones educativas, que son sus principales líneas de investigación.

Dirección de las autoras: Sonia Lara

Departamento de Educación. Edificio

Biblioteca. Universidad de Navarra.

Campus Universitario 31080. Pamplona.

España

slara@unav.es

Sonia Rivas

Departamento de Educación. Edificio

Biblioteca. Universidad de Navarra.

Campus Universitario 31080.

Pamplona. España 


\section{srivas@unav.es}

Fecha recepción del artículo: 13. enero. 2009

Fecha aceptación del artículo: 17. marzo. 2009 